\title{
WHAT IS THE RESPONSIBILITY OF MATHEMATICS EDUCATION TO THE INDIGENOUS STUDENTS THAT IT SERVES?
}

\author{
Tamsin Meaney and Deb Evans \\ Malmö University and Charles Sturt University
}

\begin{abstract}
Although refuted many times, the commonly accepted story about Indigenous communities in Australia is that they had few counting word and thus were lacking in ways to quantify amounts. In this paper, we use the case of quantifying to discuss how Indigenous mathematics can be used, not just to help Indigenous students transition into the classroom but also back into their home communities. We argue that mathematics education must take seriously its responsibility to support Indigenous students to gain school mathematics and also to help maintain the use of traditional mathematical ideas. If this does not occur, mathematics educators will contribute, intentionally or unintentionally to the loss of Indigenous knowledge that present and future generations of Indigenous people will hold them responsible for.
\end{abstract}

\section{Preface}

For mathematics education researchers, as with all researchers, life experiences impact the positionality we bring to our work-they inform the questions that we ask, the data we choose to gather, and the interpretations we draw. (Foote \& Bartell, 2011, p. 63)

In 2010, Tamsin with her family visited the remote community where she had taught almost twenty years previously, something she had done irregularly, since she moved away at the beginning of 1994 . This time she returned with her son, who had been seven when they moved to Alice Spring, and the intention was to catch up on the happenings of the family who had adopted them and with whom they had spent many week-ends gathering bush tucker. Just as they were pleased to see their white son, Michael, Tamsin was pleased to see her extended Aboriginal ${ }^{1}$ family. Tamsin's Aboriginal son was now grown with a family of his own and his mother, Tamsin's sister, had retired from working at the school. It had been Tamsin's sister who had given her the Pitjantjatjara name of Itjawalyi.

The community told of their anger at the Federal Government's Intervention and how it made them feel like second class citizens (see Aboriginal and Torres Strait Islander Social Justice Commissioner, 2007). They also talked about removing the school from the auspices of the Northern Territory Department of Education because of the policy of allowing only English to be used for the first 4 hours of the school day (Edmonds-Wathen, 2011). This community had run a successful bilingual program since the 1970s where children became literate in their home language and in English. This community felt that their needs were not being met through current government policies. Like other Indigenous communities throughout the world, they

\footnotetext{
${ }^{1}$ In Australia, there are a large number of distinct Indigenous groups with their own languages and cultures. In the past, these groups have been labelled as Aboriginal and Torres Strait Islander peoples but with a recognition that they were made up of many different cultural groups. In this paper, we have tried to use the most appropriate terms for the people whose quantification practices we describe. Regardless of whether they are general terms, such as Indigenous, or specific terms, such as Wiradjuri, the labels all begin with a capital letters to show respect for these groups. However, many of our sources are old and the use of racist terms is prolific. In quoting from these sources, we have left in the original terms but recognise that they are offensive.
} 
were prepared to fight for control of their school (see Holm \& Holm, 1990; Meaney, Trinick \& Fairhall, 2011).

The academic success of the community was reflected through Tamsin's Aboriginal son gaining his mining truck driver's license. Having been one of this young man's teachers, Tamsin had contributed to him having the academic skills, including the mathematics skills, needed to gain the truck license. With this license, he was seeking work at a mine in South Australia and would take his family with him. Hardly surprising, this success story was not viewed as such, by his mother who was about to lose regular contact with her grandchildren. For her, it was a time of great pain.

When Tamsin returned to New South Wales, she discussed the situation with Deb, a Wiradjuri woman, involved in the resurrection of her traditional language. We discussed how a "success" story, such as this, was likely to contribute to the loss of Indigenous cultures as children would grow up without contact with their community's language and the land connected to that language. We wondered whether in 50 years time, we would be lamenting the demise of all Australian Indigenous languages and cultures because of the success of policies, which saw academic qualifications as the sole purpose of schooling. Tamsin reflected on her contribution, through her teaching, to this assimilation story. As a non-Indigenous person working in Indigenous education, reflection is a constant and necessary part of being an educator (Meaney, 2004a; 2004b). With Deb, these discussions became about possible alternatives. Surely, as raised by the famous Indigenous Australian Mick Dobson (1993), there had to be other options that allowed for Indigenous students to gain both Western academic qualifications and retain their own community's Indigenous mathematical understandings and practices. This paper is a result of these discussions and reflections.

\section{Introduction}

In this paper, we argue that it is flawed notion to perceive the gaining of the same achievement levels in national mathematics tests as non-Aboriginal Australians by Aboriginal children, in remote communities of Australia, to be the pinnacle of school success. Mathematics educators needs to take seriously both their role in supporting students to transition into the wider Australian society and also the need for these students to remain strong members of their home community. Without this joint aim, mathematics remains as Bishop (1990) wrote "one of the most powerful weapons in the imposition of western culture" (p. 51). In this paper, we use information on quantifying in traditional Australian Indigenous cultures to propose a research agenda for determining an education in mathematics that would support both aims.

Emphasis continues to be placed on Indigenous students' underachievement in mathematics (Meaney, McMurchy-Pilkington, \& Trinick, 2012), something that has been documented for many decades. However, as outlined by Leder (2012), the lumping together of all Australian Indigenous students as one group means that intergroup differences are hidden, with the equivalent performances of Indigenous students with non-Indigenous students in metropolitan areas remaining unacknowledged in media reports. Media highlighting of this underachievement has intensified with the introduction of National Assessment Program-Literacy and Numeracy (NAPLAN). The results from these tests allow comparisons to be made between schools and education systems in ways that had not been possible previously. However, there have been criticisms of NAPLAN use with Indigenous students, in 
regard to the knowledge that it tests (Edmonds-Wathen (2010) and the way that testing is conducted (Klenowski, 2009). Regardless of these concerns, the success of programs implemented within remote communities frequently is connected to improvements in NAPLAN results. Like Radford's (2012) troubling of notions of emancipation in education, the idea that improved school results are the most important indicator of Australian Indigenous students' success needs to be troubled.

Although we acknowledge the importance of Indigenous students gaining school mathematics qualifications, we consider that focusing solely on improving NAPLAN results is problematic for two inter-related reasons. The first is about the purpose of education and its relationship to school education. Kemmis (2009) described the role of education as contributing to the good for both the individual and for the society in which the individual lives. When this good is seen only in relationship to Western perceptions of economic benefits to the individual and the society, then the potential of this good is restricted. Using the ideas of Marx, Radford (2012) stated:

In the transportation of the market paradigm into the school, curricular knowledge becomes more and more reduced to that which can be translated into economic terms. ... In accordance with the capitalist forms of life, the emphasis is on material advancement in detriment to a genuine social dimension: within the contemporary liberal orientation, we see that in society and in our schools. (p. 109)

Indigenous communities also support an economic rationalisation for education-"we are aware that effective mathematics teaching is crucial for Indigenous students' futures as mathematics performance can determine employment and life chances" (Matthews, Cooper, \& Baturo, 2007, p. 250). Nevertheless, these communities state that education also must include the strengthening of their Indigenous culture (Sarra, 2003). The problem, as many Indigenous young people see it, is that they are not able to ensure that their need for their Indigenous culture to be strengthen is recognised or acted upon by those who control education policy making (Higgins, 2005). In 1984, Paul Hughes, then chair of the National Aboriginal Education Committee, stated:

We warn that unless educational authorities professionally recognise and take action upon the issues we raise the current inadequate situation for Aborigines in education will be perpetuated. The National Aboriginal Education Committee asserts that our people deserve the right to their own Aboriginal identity, and to academic success. (p. 2)

In the years since Hughes made this address, little improvement in achieving both aims seems to have occurred. This is possibly because of the difficulties in knowing how to achieve this in relation to mathematics (Morris \& Matthews, 2011). In discussing the needs of students transitioning between contexts, Meaney and Lange (2012, forthcoming) argued that mathematics education should not just be concerned with easing students into mathematics classrooms but also in supporting those students' transitions back into their home communities. For example, while pedagogical practices similar to those within Indigenous cultures can be used to support students to transition into the mathematics classroom (see suggestions by Sayers, 1983 for example), they do not necessarily help them transition back to their community context. If these pedagogical practices gain value only because they support the gaining of school mathematical knowledge, then they become devalued as Indigenous practices in their original contexts. Therefore, mathematics education, rather than serving the needs of Indigenous students and their communities, hijacks what is perceived as the 'good' of an education by presuming that school mathematics is what will provide it. 
The second issue with only valuing the gaining of school mathematics is that it can contribute to the loss of knowledge about Indigenous mathematics. There is continuing debate about the existence and value of mathematical forms of knowledge that did arise outside of Western cultures (Rowlands \& Carson, 2002; Radford, 2008). In Australia, there has been a long tradition of denying Indigenous mathematical knowledge (see Pickles, 2009; Deakin, 2010). As Dame Mary Gilmore (1963), the Australian poet, noted in her recollections of her childhood in the 1870s about learning to count the stars with Wiradjuri children:

To know and number the stars was a part of the training of the children, and it began in infancy. The heavens were as much the clock and chart of these people as roads, timepieces, and calendars are ours. But the ordinary white man who counted to a hundred and then notched a stick because otherwise his mind lost the place, could not conceive of a method of reckoning other than his own. So, he said of what he could not grasp, that "the aborigines could not count." (p. 128)

By denying that there was or is mathematics knowledge within Indigenous cultures, mathematics educators reinforce the view that the teachers' job is to teach only school mathematics (see Deakin, 2010). Mathematics educators are excluded from having to consider how they contribute to the loss of Indigenous cultures because they do not recognize that there is anything that could be destroyed. Consequently, the denying of Indigenous mathematical knowledge and practices absolves mathematics educators of their responsibility to consider cultural destruction as a possible outcome from their teaching of school mathematics. In this way, the damage caused by concentrating on Western mathematics, Bishop's (1988) secret weapon of cultural imperialism, remains unrecognised.

In this paper, we use examples of quantifying to explore the possible contribution that these ideas could make to the education for the good of the individual and for the good of the society. Our analysis compares how quantification and how it could be learnt are perceived in Western mathematics education with what is known about how some Australian Indigenous groups quantify. We do this for two reasons. The first is to show that quantification practices were documented for many Australian Indigenous groups and to reinforce the point made by Harris (1990) that they should not be ignored as though they did not exist. The second is to raise alternatives to how quantifying could be taught so that Indigenous and nonIndigenous students have a range of possibilities to become numerate members of the societies that they belong to.

In this paper, we use information from anecdotal accounts, such as those of Mary Gilmore, as well as ethnographic records and review papers on Indigenous mathematics. Much of this work was documented by non-Indigenous researchers and people at different historical times. As Nakata (2007) warned, the documenters' own cultural background influenced what they attended to and how they described it. This has an impact on the points that can be drawn from this information-and why we felt it was so necessary to include the story at the start to this paper. Whilst acknowledging this warning, we feel that this information still has some useful points to make. Although we discuss more specifically issues in regard to remote communities, such as the one where Tamsin taught, there are also implications for Indigenous people living in urban centres, such as where Deb works, as well.

Life in Aboriginal Australia is characterised by the experience of biculturality over notions of identity. I argue that this experience enhances the emotional charge of mathematics learning for Aboriginal people. The values encoded in mathematics challenge the values of Aboriginal Australia in a profound way, and imbue the learning of mathematics by Aboriginal people with a high degree of emotional conflict. This occurs 
irrespective of whether the Aboriginal person is part of a Homeland community, or lives a

life embedded in the processes of European Australia. (Watson, 1988, p. 271)

\section{Quantification}

In school mathematics, quantifying amounts is thought to begin by counting and then extending to understandings of number systems (Linder, Powers-Costello, Stegelin, 2011). Consequently, counting is perceived as a necessary precursor to calculating amounts through, for example, addition, subtraction, multiplication and division. Clements and Sarama (2007) stated:

Accurate, effortless, meaningful, and strategic counting is an essential early numerical competence. Initial level of achievement and subsequent growth in number and arithmetic from preschool into elementary years are both predicted better by early counting ability than by other abilities, such as visual attention, metacognitive knowledge, and listening comprehension. (p. 478)

In recent years, the pre-eminent role given to counting in calculations, especially multiplication and division has been under debate (Confry \& Smith, 1995; Dougherty \& Slovin, 2004; Siemon, 2011). Davydov (1975) suggested that measurement could be an alternative to counting for children to develop understandings of equal and unequal amounts. Nevertheless, in Australia, understandings of quantifying are built on the ideas outlined by Clements and Sarama (2007) (Siemon, 2011).

In contrast to these ideas about counting, we argue that, in many traditional Australian Indigenous cultures and languages, quantification occurs through pattern recognition and estimation of discrete amounts. Using Mary Gilmore's term, we label this type of quantification "reckoning".

Before continuing, a word of caution is needed. All Indigenous languages and cultures should not be considered to share the same ways of reckoning and/or counting. The information, that we draw upon, comes from a variety of different Australian Indigenous language and cultural groups, suggesting that there were some similarities across the groups. However, this should not be taken as an indication that all Indigenous people traditionally quantified in this way. As well, with changes in living conditions, it is the case that some traditional practices have been replaced or modified. Instead, as is suggested in the final section of this paper, research with different Indigenous groups is needed to document traditional reckoning strategies.

\section{What do we know about quantifying in Australian Indigenous cultures?}

Although in this paper, we concentrate on reckoning, it is only one form of quantification that can be found in Australian Indigenous cultures. Other examples of quantification have been noted in pronouns, birth order naming and in counting systems and we describe these briefly in this section.

In many Aboriginal languages, pronouns enable distinctions to be made between the number of people participating in a situation. For example, Pitjantjatjara, like many Western Desert languages, distinguishes between the number of people being discussed (Eckert \& Hudson, 1988). The pronouns for 'we' differ depending upon whether it was the speaker and one other or the speaker and more than one other. Similar distinctions can be made about the number of people referred to through the pronouns, "you" and "they'. In Wik-Mungkan, the language of Aurukun, the dual pronouns, pula (those two) and ngala (I and you or we two) refer to exactly two people (Sayers, 1983). Rudder (1983) reported the case that in Dhuwal and 
Dhuwala languages of North-East Arhemland that the pronouns also could refer to groups of exactly three people.

Birth-order naming illustrates another form of quantifying. In several Australian Indigenous languages, one of the names given to children indicated their position in the family. McKenzie (2007), an Adnyamathanha man, indicated that his name, Virdianha, meant that he was a male and the first-born child in his family. A first-born girl child would have been called Arranyinha. He gives birth-order names for up to ten children. McKenzie suggested that each name was also that of an ancestor and consequently included indications of the sorts of responsibilities that the person with that name should take on. Woerlee (2000) described similar associations for birth order names of the Kaurna people, also of South Australia.

There has been a long discussion over more than a century about whether Australian Indigenous cultures and languages have counting words. However, the need for such a debate needs problematising, given that there were early documentary evidence of numbers larger than three (Harris, 1982; McRoberts, 1990). Harris (1987) and Pickles (2009) related how early ethnographers' own preconceptions, of what they would find, blinded them to the number terms that were available in different cultures. Harris (1987) cited Haddon who had lead an expedition to the Torres Strait in the nineteenth century and who was provided with names for 100 and 1000 but refused to believe that they were possible. Similar refusal to accept information provided by informants seems to have occurred when body part numbering systems were recounted to other anthropologists (Hammarström, 2010). Howitt (1904) recalled the use of a body counting system to illustrate the numbers of days a messenger had been travelling:

This method of counting seems to do away with the often-repeated statement that the Australian Aborigines are unable to count beyond four or at the most five. By the above manner of counting they are able to reckon up to thirty, with names for each place. ( $p$. 698)

On the other hand, this does not mean that counting in Australian Indigenous cultures is/was done in the same way or solved the same sorts of problems as is the case in Western cultures (Hunting, 1987). Hunting (1987) discussed how "Western number words have imbued in them meanings which include the dual possibilities of both cardinal and ordinal qualities" (p. 8) whereas Yolngu counting systems, as reported by Rudder (1983), were considered to only have cardinality meanings associated with them. "Discrete quantities are evaluated on the basis of patterns of perceptual items rather than by counting process, using a mechanism called subitising" (Hunting, 1987, p. 8). Subitising is usually considered to be the ability to instantly recognise the quantity in a small group (Warren, deVries \& Cole, 2009). As is seen in the next section, some Indigenous people are able to recognise much larger groups of numbers without recourse to counting.

Misunderstandings about what counting represents-cardinal and ordinal or just cardinal - derive not from the culture in which these counting practices develop but from those interpreting them, as had been the case of some anthropologist in the nineteenth and twentieth centuries. If a teacher expects a number label to include an understanding of ordinality, then when children are unable to discuss numbers which become before or after, using these ordinality understanding, then it is often the child who is considered to have the problem. Instead, it would be better to recognise that the issue lies with the teacher misunderstanding how the counting words are used by the children. In 1998, Tamsin wrote about how children at Maningrida, in central Arhemland, were competent in counting in English from a young age but that number 
words seemed to be learnt as separate labels (Roberts, 1998). "Three" was a label that could be attached to a group of three objects, but there did not seem to be an understanding that three was one more than two or one less than four. Many Indigenous languages do not have terms for "more than" or "less than" (Christie, 1995) making understandings about one more than or one less than difficult to translate from English. However, it requires the English-speaking teacher to accept that there might be differences in order to understand how counting is being used.

Differences in expectations about what is being discussed can occur when interlocutors are working from different world views (Roberts, 1998). Counting as a form of accumulation, as is the case in Western cultures, may be of less importance in some Australian Indigenous cultures. Harris (1987) suggested that in some circumstances, counting should be seen as more purposefully connected to division, because of the priority given to sharing in some communities. This proposition arose from the story reported by Stokes (1982) of an old women who when asked about the purpose of counting immediately described it as sharing and connected this to a dreaming story about a dog who could count in order to share turtle eggs among members of his family. To try to interpret mathematical practices, such as quantifying, without an understanding of the problems to which they are/were connected, risks that these practices will continue to be misinterpreted and/or devalued (Radford, 2008).

\section{Quantification through reckoning}

Although there are other aspects of quantifying in many Australian Indigenous cultures, the one that occurs most often in documentary evidence is that of pattern recognition and estimation, which we have labelled reckoning. Reckoning has the possibility of quantifying in a way that respects the relationship between the person quantifying and the objects being quantified. Sayers (1983) suggested that at Aurukun, people had relationships with individual objects and so the need to quantify with a specific label for an amount, as is done through counting, was unnecessary. She related the story of her neighbour who continually got into trouble with the police restriction on the number of dogs he could own because he was never sure how many he had. Each dog was an individual to him and so to count them was inappropriate. Quantifying through reckoning avoids this concern and draws on several related strategies: spatial reconstruction; recognition of smaller groups; and visual patterning.

There are several anecdotal stories, like that of Mary Gilmore (1964), which suggest that reckoning was part of many Australian Indigenous cultures. In a handout from the South Australian Department of Education and Child Services (undated), there is a story about an Aboriginal Education Worker in Cooper Pedy who talked with a local Aboriginal man about the number of cattle he had. The Aboriginal man first said that he had tjuta, meaning lots, but after being asked for a precise amount went away and brought back stones to correctly indicate the exact number of cattle he had. Harris $(1982 ; 1987)$ cited Strehlow (1944) as requesting some Western Arrente men to name groups of $10,20,30$ and 40 , which they did with specific terms and hand signals. In both stories about quantifying, it was assumed that it had been done without counting, although it is not clear that this was in fact the method that was used. Nevertheless, Strehlow (1944) was critical of the terms provided to him because they could be applied to approximate as well as exact amounts. Yet, even in Western cultures distinctions between specific and approximate amounts are not always clearcut or necessary. Siemon (2011) discusses the difference between quantifying to 
determine how much, which can be answered by determining relative amounts, rather than how many, which require a specific amount as an answer.

In recent research, some Indigenous children used non-counting methods to determine quantities. Butterworth and Reeve (2008) investigated the strategies of Indigenous children whose first language was Walpiri, from Central Australia, Anindilyakwa, from Groote Eylandt, or English, from Melbourne, in reproducing amounts of items that a research assistant had shown them and then covered. They found that the children from remote communities were significantly more likely to use a spatial arrangement similar to the one shown to them by the research assistant to reproduce a group of objects. Competent younger children from these remote communities used spatial arrangement all the time, whilst older children used a variety of strategies depending upon the task. In contrast, Indigenous children from Melbourne used a counting strategy for every task.

Using tasks that tested the ability to recall temporal or spatial sequencing, Davidson and Klitch (1980) found that remote Indigenous children preferred spatial sequencing whilst white urban children used temporal sequencing. Building on the work of Kearins (1976), Davidson and Klitch hypothesised that this was due to the need for these children to develop significant spatial awareness in order to survive in the desert. However, other researchers queried Kearin's results suggesting that there may be different causes for spatial memorisation abilities, such as, in some communities, the playing of a game requiring these skills (Knapp \& Seagrim, 1981).

Treacy and Frid (2008) investigated whether children from a Wangkathaspeaking community in Western Australia, were able to determine the correct amount of witchetty grubs to be given to a group of people represented in a picture so that each person got one grub. The pictures showed groups of 4, 6, 10 and 16 people. Of the eighteen children interviewed, all except one could orally count past 16 , half of them could count past 100. Nevertheless, Treacy and Frid (2008) stated:

It is interesting to note that most of the children did not choose to count for this task. Of those that did not choose to count, most of them were able to select the exact number of maku [witchetty grubs] needed each time, or to select one more or one less than required. This suggests that for most of these children, counting is not an appropriate strategy for this type of situation. (p. 535)

When asked how they worked out the number of grubs, most children stated that they just looked at the pictures. One girl when encouraged to elaborate on her explanation stated that in the picture, she had recognised that there were 5 men, 6 women and 5 children. This suggests that unlike the remote community children in Butterworth and Reeve's (2008) study, this child may not have used a spatial arrangement to determine the amount that she needed. Instead she saw the larger groups as being composed of smaller groups and may have used subitising strategies to ascertain how many were in each of these smaller groups.

There is evidence from other school situations, that not all Western children use counting to solve number problems. Confrey and Smith (1995) discussed the idea of splitting as an alternative to using counting as a basis for some multiplication and division problems. In the background to their research, they describe a second grade child who places candies in an array in order to determine how many each of the four members of her family would receive. Visually being able to determine the equivalence of the groups was an important component of this child's strategy. Counting is just one method for solving these sorts of problems and in some cases it may not be the most efficient or effective method. 
Although not traditional activities, card games ${ }^{2}$ played in Indigenous communities also have provided information about reckoning. To play these games, Indigenous people used pattern recognition to determine amounts. This pattern recognition may have included both spatial sequencing and recognition of groups of specific amounts within larger groups. However, like the previous research discussed, there is little information about how Indigenous people actually determine the amounts.

In the 1970s, there was much interest in how Aboriginal people, in communities, played the very common card games that were associated usually with gambling. In 1976, Holm and Japanangka described a card game played at Hooker Creek in the Northern Territory. In this game for eight players, the court cards are discarded and the Ace has a value of 1. Each player receives 5 cards and, using 3 of those cards, must make a tens number, such as 10, 20 or 30 (the suit of the card is unimportant). Although 10, 20 and 30 have individual names in the game (Davidson, 1979), the actual amount of tens is irrelevant, it is the zero amount of ones that is of interest (Sayers, 1983). If players are unable to make a tens number then they are out of the game and their money is lost. If they can make a tens number, then they progress to the next stage which involves them determining their number from the two remaining cards in their hand. Their number comes from totalling the two cards and noting the ones digit. So for instance, having a total of 8 would be a higher number than 15, because the tens number is irrelevant. The person with the highest number wins the game (and the money) (Davidson, 1979). Although gambling is an integral part of the game, it is the build up of suspense that players appreciate, at least at Bamyili (Davidson, 1979). Similar card games, where the most valuable number is determined from the ones number, have been described from at least the 1940s (Brendt \& Brendt, 1947; Cooke, 1990; Davidson, 1979; McRoberts, 1990; Sayers, 1983).

Davidson (1979) conducted an extensive analysis of card playing at Bamyili in the Northern Territory. Although Bendt and Bendt (1946), Holm and Japanangka (1976) and McRoberts (1990) presumed that Aboriginal people used a form of addition to determine the amount, Davidson (1979), like Sayers (1983) and Hughes (1984), concluded that Aboriginal people used pattern recognition. The way that cards were held meant that the patterns were only partially visible. However, card players used information from the visible parts of the cards to determine their value and then to use their knowledge of combinations of cards to determine the number for the specific combination that they held.

Cooke (1990) suggested that when people learnt to play the card game that they may have used addition skills, but over time this way of determining the number was replaced by pattern recognition. However, Sayer's (1983) discussions with the teachers at Aurukun, in Queensland, did not indicate that children, who were learning to play the game, could use addition skills at the time. Davidson's (1979) informants were also adamant that his informants did not use addition, but rather knowledge of combinations to determine their number. It seems that the number labels given to

\footnotetext{
${ }^{2}$ Concerns about card playing means that many Indigenous communities are unlikely to support their use for teaching quantification in schools (Meaney, McMurchy-Pilkington \& Trinick, 2008). However, the fact that several studies were carried out on how Indigenous people quantified the winning amount makes card game investigations a useful source of information about reckoning. These investigations may have arisen because card playing was considered a Western activity but it was clear to the investigators that it was not played in a Western way.
} 
different combinations described patterns, rather than an abstract quantity. The labels, if anything, represented discrete amounts, which did not recognise any relationship between different amounts, except that of relative magnitude (Siemon, 2011). Eight may win against 5 and against 2, but the fact that there is a difference of 3 between 8 and 5 and of 6 between 8 and 2 is of no interest or importance.

In some parts of Australia, pattern recognition was considered to be connected to discrete amounts, more explicitly. Mary Gilmore (1963) provided an intriguing insight into such a connection:

\begin{abstract}
When I was with the aboriginals on the banks of the Murrumbidgee ... the chief woman of the tribe ... tried to teach me to count in the native way. She began as she would with her own children, showing me two fingers, two sticks laid together, two eyes, two ears, two elbows, two feet. She did not show me two thumbs, then, as thumbs had a group meaning and she did not want to confuse me. Later she used tiny sticks, fragments of bark, and little clods of earth. This was to show that through differing shapes or differing places two remained two; and it was also to make the eye quick in perception. As soon as I grasped two I went to threes.
\end{abstract}

$\cdots$

So accurate was my counting as a result of this group notation, that later on, when between seven and eight years of age, John Stinson, of Kindra, used to take me with him to tally the sheep at the yards, or when there had been boxing with travelling sheep. I counted by threes (I had got no further at the camp, though I remembered the method and later on practised on sheep up to fives). My tally was never questioned. Indeed it was by the blacks' method all the good tally-men of the old days learned. Most counted by twos; a few by three; none by fives, as the mind of the white man, untrained in the higher numbers, inelastic by age, and feeling its only security in the unitary method, feared to leap beyond the easy and the accustomed. To me it seemed easy to miscount by ones easy to miss a single sheep - impossible to miss three, four or five; though I was surest with three. As a matter of fact I thought it waste of time to say one, two, three, four, when I could say three, six, nine and so on (p. 128-129)

The research on Indigenous reckoning methods discussed in this section suggests that quantifying was and still is, in some remote communities, a part of daily life in many Indigenous communities; albeit, in ways that are different to those found in school mathematics. Even in cases where there are extensive counting systems, amounts seem to be considered discrete entities and the relationship to other amounts restricted to a recognition of their relative magnitudes. Differences in what kind of responses are expected and valued are related to the different sorts of cultural purposes that quantifying was used for (Radford, 2008).

Spatial arrangements with pattern recognition, including seeing smaller amounts within a larger whole can contribute to identifying larger amounts than is normally considered possible through subitising. These quantifying skills allow for the determining of very large and/or exact amounts when the situation required it. At other times, these skills enable a close estimation to be made. In considering how education for Indigenous people can contribute to the good for the individual and the good for the society, then it is no longer appropriate to ignore the fact that reckoning as a form of quantifying can be used to determine an exact and approximate amount of items. It is important to consider how this information can be used to support Indigenous students, whose communities used such strategies, not only to transition into mathematics classrooms but also back to their home communities.

\title{
Implications
}

If mathematics education is to contribute to the good of individual Indigenous students and to the good of their communities, then there is a need for stronger 
commitment by researchers to work with their communities. Although much work in mathematics education for Indigenous students is being undertaken in Australia, almost all is focussed on improving academic results by concentrating on Western ways of teaching mathematics (Meaney et al., 2012). This may lead to the easing of the transition of these students into mathematics classrooms but not necessarily back into their home communities (Meaney \& Lange, 2012 forthcoming). Consequently, if mathematics educators are to take seriously their responsibilities to Indigenous students then a different approach needs to be taken.

As a beginning, we suggest a three-pronged research program to support the use of Indigenous ways of reckoning being incorporated into mathematics education programs. The first is to discover what reckoning strategies continued to be used or have been used in the past. The second prong is to determine how reckoning practices could be connected to Western calculating and the third is to develop strategies for maintaining traditional mathematical practices. All of these research approaches need to be controlled by Indigenous people, with the support of non-Indigenous people when needed. As Nakata (2007) stated "an important aspect of Indigenous Knowledge that is overlooked in some definitions is that Indigenous peoples hold collective rights and interests in their knowledge" (p. 185). It is important that they have control, at all times, over what knowledge is discussed and how it is used.

In many ways, the first prong of the research agenda may seem obvious as it is to determine what quantifying practices are still being used and those that had been used in the past. The assumption that Australian Indigenous people did not calculate because they had no counting names has meant that in 2011 there is a dearth in understanding about how reckoning was done. Mathematics education researchers have contributed to this loss of knowledge by not taking seriously the task of finding out what practices operated in the communities and in which children were engaged. Collaborations between Indigenous communities and mathematics educators, Indigenous and non-Indigenous, need to discuss what could be quantifying practices and how they could be documented. Forms of quantifying, such as pronouns to indicate the number of participants and birth order names, fulfil a variety of functions and therefore any investigation needs to broad in its approach. In communities where reckoning practices are still in use, there may be a need to document what these practices are and the functions that they fill. In communities where reckoning practices may be known to only a few elders or seemingly lost altogether, archival records could be used to determine what was known. There are a significant number of Indigenous communities who still use their traditional languages as well as communities who may have lost much of their language, but retain cultural links to traditional forms of quantifying. In trying to document what quantifying practices are or were part of different Indigenous cultural practices, it is important that it is not assumed that all Indigenous groups would have quantified in the same manner.

If children are exposed to different quantifying practices in their home communities, they will bring these to school. Children do not arrive in mathematics lessons as empty vessels (Bucknell, 1995; Treacy \& Frid, 2008). Instead they draw on their out-of-school experiences when they participate in counting activities at school and resume participation in reckoning activities when they leave the classroom. Treacy and Frid (2008) suggested that the teachers of the children that they tested were not able to provide appropriate lessons because they did not recognise the prior knowledge and practices with which the children arrived at school. Western beliefs about progressions for learning about number limit the possibilities for developing 
alternative progressions starting from Indigenous understandings about quantifying. For example, it might be possible for Indigenous students' who are able to separate numbers into smaller components, to connect this to being able to recognise the amount of tens and ones in a large amount. Such an approach could be linked to the place value system of the Hindu-Arabic numbers. For example, Mary Gilmore (1963) described how she had been able to combine her understanding of Wiradjuri counting with that of Western calculating.

When I went to school in Wagga Wagga, the speed with which I did addition sums was noted, and at last Miss Galloway came to my class (I was then in second) and asked how I did it. I did it by breaking the ordinary units into a group-unit. That is to say, in a column of $6,9,4,5$, there would be seven threes and three over. If fives or tens suited better I used fives and tens; these latter being for double columns. Unconsciously I had carried into the school the method of the blacks; to the so-called educated the accuracy and speed of the so-called ignorant. (p. 129)

Such possibilities are intriguing but more research needs to be done to determine what sorts of connections could be made. However a number of cautions must be embedded into this research. Without consultation with the community, the use of community-based activities, as a vehicle for teaching school mathematics "can result in the original purpose of the activity becoming lost or denigrated through the concentration on the Western mathematical idea 'seen' to be embedded within it" (Meaney, 2002, p. 170). As well, using traditional mathematical practices in schools can alter the practices. In one area of Papua New Guinea, Esmonde and Saxe (2004) found that the local counting system, based on body parts, had been included in community schools' mathematics lessons, but in so doing the structure of the counting system was altered to match more closely the base ten of the Hindu-Arabic system. Therefore, the use of traditional Indigenous mathematical practices needs to be included in mathematics classrooms as a collaboration between teachers and community members.

The third need for research is to consider how traditional quantifying practices can be maintained or restored as legitimate contributors to mathematics education in schools. Much knowledge of Indigenous quantifying practices has been lost in the years since Howitt (1904) highlighted how statements about Indigenous people not having counting practices were incorrect. Mathematics educators have a responsibility to ensure that more than Western mathematical ideas are discussed in mathematics classrooms. In Australia, these discussions should not just occur in Indigenous classrooms but non-Indigenous children would also gain from learning about efficient and effective alternatives for quantifying. However, how this can be done needs to be researched and understood better. Quantifying through reckoning was done to fulfil specific purposes. To try to teach these quantifying practices away from an understanding of their purposes is likely to trivialise those practices:

Teachers must be careful that they do not introduce cultural applications as examples of "quaint customs" or "primitive practices". ... They must inspire students to think critically about the reasons for these practices, to dig deeply into the lives and environment of the people involved. It is so easy to trivialize the concept of multicultural education by throwing in a few examples as holidays approach. (Zaslavsky, 1973, p. 53)

If Indigenous students are to be supported to transition into mathematics classrooms and back to their home communities then researching all three prongs of this research agenda is important. Without such an approach then there is a risk that school mathematics remains the secret weapon of Western imperialism. As Christie (1995) suggested: 
Pedagogy outside imperialism depends upon, first of all, abandoning the "teaching causes learning" paradigm. Yes learning does occur when there is some collusion between teacher and student, but that happy circumstance is not determinable in advance by the teacher. This of course creates real problems for curriculum writers.

Secondly, this pedagogy depends on the forum, a site where different voices, different perspectives can be heard, and the community as well as individuals work on exploring, creating and celebrating their knowledges.

Finally, the pedagogy depends on the centrality of the speaking subject - the possibilities for performance on the part of the students. Outside their own performance they are learning to map other people's territories. (p. 9)

In this way, mathematics educators, including researchers, through the schooling that they promote can become active contributors to supporting an education for the good of the individual and the good of the society, in a far broader manner than simply valuing its potential economic benefits. As stated at the beginning of the paper, our own life experiences affect the sort of research we undertake and the data that we focus on (Foote \& Bartell, 2011). However, the assumptions that such life experiences engender within us need to be questioned continually if we are to educate as ethically as our students, Indigenous and non-Indigenous, need us to be.

\section{Acknowledgments}

We would like to thank Luis Radford, Di Siemon, Jan Thomas for their insightful and helpful comments on an earlier version of this paper.

\section{References}

Aboriginal and Torres Strait Islander Social Justice Commissioner (2007). Social justice report, 2007. Canberra: Australian Human Rights Commission. Retrieved from http://www.hreoc.gov.au/social_justice/sj_report/sjreport07/index.html

Bishop, A. J. (1990). Western mathematics: The secret weapon of cultural imperialism. Race \& Class, 32(2), 51-65.

Berndt, R. N., \& Berndt, C. H. (1947). Card games amongst Aborigines in the Northern Territory. Oceania, 17, 248-269.

Bucknell, G. (1995). Building bridges between Aboriginal and Western mathematics. The Aboriginal Child at School, 23(1), 22-31. Retrieved from http://www.aiatsis.gov.au/lbry/dig_prgm/e_access/serial/m0009540_v_a.pdf

Butterworth, B., \& Reeve, R. (2008). Verbal counting and spatial strategies in numerical tasks: Evidence from Indigenous Australia. Philosophical Psychology, 21(4), 443-457.

Confrey, J., \& Smith, E. (1995). Splitting, covariation, and their role in the development of exponential functions. Journal for Research in Mathematics Education, 26(1), 66-86.

Cooke, M. (1990). Seeing Yolngu, seeing mathematics. Batchelor, NT: Batchelor College. Retrieved from http://www.aiatsis.gov.au/collections/exhibitions/ethnomathematics/m0069594_a html

Christie, M. (1995). The purloined pedagogy: Aboriginal epistemology and maths education. Paper presented to the Annual Conference of the Mathematics Education Research Group of Australasia, Darwin.

Clements, D. H., \& Sarama, J. (2007). Early childhood mathematics learning. In F. K. Lester (Ed.), Second handbook of research in mathematics teaching and learning (pp. 461-555). Charlotte, NC: Information Age. 
Davidson, G. R. (1979). An ethnographic psychology of Aboriginal cognitive ability. Oceania 49(4), 270-94.

Davidson, G. R., \& Klitch, L. Z. (1980). Cultural factors in the development of temporal and spatial ordering. Child Development, 51(2), 569-571.

Davydov, V. V. (1975). Logical and psychological problems of elementary mathematics as an academic subject. In L. P. Steffe (Ed.), Children's capacity for learning mathematics. Soviet Studies in the psychology of learning and teaching mathematics (Vol. VII, pp. 55-107). Chicago: University of Chicago.

Deakin, M. (2010). Aboriginal and Islander mathematics: Comments on one aspect of the proposed National Curriculum. Gazette of the Australian Mathematical Society, 37(4), 233-237.

Dodson, M. (1993). Annual report of the Aboriginal and Torres Strait Islander social justice commissioner. Canberra: Australian Government Publishing Service.

Dogherty, B., \& Slovin, H. (2004). Generaliszed diagrams as a tool for young children's problem solving. In M. J. Høines \& A. B. Fuglestad (Eds.)

Proceedings of the $28^{\text {th }}$ Conference of the International Group for the Psychology of Mathematics Education (Vol 2. pp 295-302). Bergen, Norway: PME.

Eckert, P., \& Hudson, J. (1988). Wangka wiru: A handbook for Pitjantjatjara language learners. Adelaide: South Australian College of Education.

Edmonds-Wathen, C. (2010). The everyday language of mathematics: Investigating spatial frames of reference in Iwaidja. In M. Pinto \& T. Kawasaki (Eds.), Proceedings of the $34^{\text {th }}$ Conference of the International Group for the Psychology of Mathematics Education (Vol 2, pp. 321-327). Belo Horizonte, Brazil: PME.

Edmonds-Wathen, C. (2011). What comes before? Understanding spatial reference in Iwaidja. In M. Setati, T. Nkambule and L. Goosen (Eds.), Proceedings of the 21st ICMI Study Conference - Mathematics Education and Language Diversity (pp. 89-97), Sao Paulo, Brazil, 16-20 September 2011. Retreived from: http://researchbank.rmit.edu.au/view/rmit:14763

Esmonde, I., \& Saxe, G. B. (2004). 'Cultural mathematics' in the Oksapmin curriculum: Continuities and discontinuities. In Y. Kafai, W. A. Sandoval, N. Enyedy, A. S. Nixon, \& F. Herrera (Eds.), Proceedings of the International Conference of the Learning Sciences 2004 (pp. 174-181). Mahwah, NJ: Lawrence Erlbaum Associates.

Foote, M. Q. \& Bartell, T. G. (2011). Pathways to equity in mathematics education: How life experiences impact research positionality. Educational Studies in Mathematics, 78(1), 45-68.

Gilmore, M. (1934). Old days, old ways: A book of recollections. Melbourne: Sirius Books.

Graham, B. (1982). Can we count on maths? The Aboriginal Child at School, 10(2), 4-10. Available from:

http://www.aiatsis.gov.au/lbry/dig_prgm/e_access/serial/m0029573_v_a.pdf

Graham, B. (1988). Mathematics education and Aboriginal children. Educational Studies in Mathematics, 19(2), 119-135.

Harris, J. W. (1982). Facts and fallacies of Aboriginal number systems. In S. Hargrave (Ed.), Language and culture, Work papers of Summer Institute of Linguistics-Australian Aborigines Branch, Series B, (Vol. 8, pp. 153-181). Darwin: Summer Institute of Linguistics-Australian Aborigines Branch.

Harris, J. W. (1987). Australian Aboriginal and Islander mathematics. Australian Aboriginal Studies, 2, 29-37. 
Harris, J. W. (1990). Counting: What can we learn from White myths about Aboriginal numbers? Australian Journal of Early Childhood Education, 15(1), 30-36.

Hammarström, H. (2010). Rarities in number systems. In J. Wohlgemuth \& M. Cysouw, (Eds.), Rethinking universals: How rarities affect linguistic theory (pp. 11-60). Berlin: De Gruyter Mouton.

Higgins, J. (2005). Why we need to get our act together and take this seriously. Keynote address to the Dare to Lead Conference, Adelaide. Available from http://www.daretolead.edu.au/DTL08_ResRead_Reading

Holm, A., \& Holm, W. (1990). Rock Point, a Navajo way to go to school: A valediction. The Annuals of the American Academy of Political and Social Science, 508, 170-184.

Holm, N., \& Japanagka, L. (1976). The mathematics of card playing in an Aboriginal community. The Aboriginal Child at School, 4, 19-22.

Howitt, A. W. (1904). The native tribes of south-east Australia. New York: Macmillan.

Hughes, P. (1984). A call for an Aboriginal Pedagogy. Presidential Address to $54^{\text {th }}$ Conference of Australian and New Zealand Association for the Advancement of Science (ANZAAS), Canberra.

Hunting, R. P. (1987). Mathematics and Australian Aboriginal culture. For the Learning of Mathematics, 7(2), 5-10.

Kearins, J. (1976). Skills of desert children. In G. E. Kearney \& D. W. McElwain (Eds.), Aboriginal cognition: retrospect and prospect. Canberra: Australian Institute of Aboriginal Studies Press.

Kemmis, S. (2009, October). What is to be done? The place of action research. Keynote address to Collaborative Action Research Network Annual Conference, Athens, Greece.

Klenowski, V. (2009). Australian Indigenous students: Addressing equity issues in assessment. Teaching Education, 20(1), 77-93.

Knapp, P. A., \& Seagrim, G. N. (1981). Visual memory in Australian Aboriginal children and children of European descent. International Journal of Psychology, 16, 213-231.

Leder, G. C. (2012). Mathematics for all? The case for and against national testing. Paper presented at 12th International Congress on Mathematical Education, Seoul, Korea. Retrieved from: http://www.icme12.org/sub/sub02_04.asp

Linder, S. M., Powers-Costello, B., \& Stegelin, D. A. (2011). Mathematics in early childhood: Research-based rationale and practical strategies. Early Childhood Education Journal, 39, 29-37.

Matthews, C., Cooper, T. J., \& Baturo, A. R. (2007). Creating your own symbols: Beginning algebraic thinking with Indigenous students. In J-H. Woo, H-C Lew, K-S Park, \& D-Y Seo, (Eds.), Proceedings 31st Annual Conference of the International Group for the Psychology of Mathematics Education, (Vol. 3, pp. 249-256). Seoul: Korea.

McKenzie, M. (2007). My Aboriginal Adnyamathanha names, English translations. Uploaded 15 November, 2007 from: http://marvynmc.multiply.com/journal/item/90/My_Aboriginal_Adnyamathanha Names_English_Translations?\&show_interstitial $=1 \& u=\% 2 F j o u r n a l \% 2 F i t e m$

McRoberts, R. (1990). Counting at Palarumpi: A survey of a traditional mathematics and its implications for modern learning. The Aboriginal Child at School, 18(2), 
19-43. Available from:

http://www1.aiatsis.gov.au/exhibitions/e_access/serial/m0005601_v_a.pdf

Meaney, T. (2002). Symbiosis or cultural clash? Indigenous students learning mathematics. Journal of Intercultural Studies Gail Fitzsimmons (Ed.), 23(2), 167-187.

Meaney, T. (2004a). The fly on the edge of the porridge bowl: Outsider research in mathematics education. In P. Valero \& R. Zevenbergen (Eds.), Researching the socio-political dimensions of mathematics education: Issues of power in theory and methodology. (pp. 167-184). Dordrecht: Kluwer Academic Publishers.

Meaney, T. (2004b). What's power got to do with it? In M. Walshaw (Ed.), Mathematics education within the postmodern (pp. 181-200). Greenwich, CT: Information Age Publishing.

Meaney, T. \& Lange, T. (2012 forthcoming). Learners in transition between contexts. In M. A. Clements, A. J. Bishop, C. Keitel, J. Kilpatrick, \& F. Leung (Eds.), Third International handbook of mathematics education. New York: Springer.

Meaney, T., McMurchy-Pilkington, C. \& Trinick, T. (2008). Mathematics education and Indigenous students. In H. Forgasz, A. Barkatsas, A. Bishop, B. Clarke, S. Keast, W-T. Seah, P. Sullivan, \& S. Willis (Eds.), Research in Mathematics Education in Australasia 2004-2007, (pp. 119-139). Rotterdam: Sense Publications.

Meaney, T., McMurchy-Pilkington, C. \& Trinick, T. (2012). Indigenous students and the learning of mathematics. In B. Perry, T. Lowrie, T. Logan, A. MacDonald, J. Greenlees (Eds.), MERGA Four-yearly review of mathematics education research, 2008-2011 (pp. 67-88). Rotterdam: Sense Publications.

Meaney, T., Trinick, T. \& Fairhall, U. (2011). Collaborating to meet language challenges in Indigenous mathematics classrooms. New York: Springer.

Morris, C. \& Matthews, C. (2011). Numeracy, mathematics and Indigenous learners. Paper presented at Australian Council for Education Research conference, Indigenous Education: Pathways to Success. Retrieved from http://research.acer.edu.au/research_conference/RC2011/8august/6/

Nakata, M. (2007). Disciplining the savages: Savaging the disciplines. Canberra: Aboriginal Studies Press.

Pickles, A. (2009). Part and whole numbers: An 'enumerative' reinterpretation of the Cambridge anthropological expedition to the Torres Strait and its subjects. Oceania, 79, 293-315.

Radford, L. (2008). Culture and cognition: Towards an anthropology of mathematical thinking. In L. English (Ed.), Handbook of International Research in Mathematics Education (2nd Edition) (pp. 439 - 464). New York: Routledge, Taylor and Francis.

Radford, L. (2012). Education and the illusions of emancipation. Educational Studies in Mathematics, 80(1/2), 101-118.

Roberts, T. (1998). Mathematical registers in Aboriginal languages. For the Learning of Mathematics 18(1), 10-16.

Rowlands, S. \& Carson, R. (2002). Where would formal, academic mathematics stand in a curriculum informed by ethnomathematics? Educational Studies in Mathematics, 50, 79-102.

Rudder, J. (1983). Qualitative thinking: an examination of the classificatory systems evaluative systems and cognitive structures of the Yolngu people of north-east Arnhem Land. Unpublished MA thesis. Canberra: Australian National University. 
Sarra, C. (2003). Young and black and deadly: Strategies for improving outcomes for Indigenous students. Deakin, Vic: Australian College of Education.

Sayers, B. (1983). Aboriginal mathematics concepts: A cultural and linguistic explanation for some of the problems? The Aboriginal child at school, 11(1), 318. Retrieved from http://www.aiatsis.gov.au/lbry/dig_prgm/e_access/serial/m0031828_v_a.pdf

Siemon, D. (2011). Developing early number ideas and strategies. In D. Siemon, K. Beswick, K. Brady, J. Clark, R. Faragher \& E. Warren (Eds.), Teaching mathematics: Foundations to middle years (pp.265-289). Oxford: Oxford University Press.

South Australian Department of Education and Child Services (undated). Aboriginal culture and mathematics. Adelaide: Author.

Stokes, J. (1982). A description of the mathematical concepts of Groote Eylandt Aborigines. In S. Hargrave (Ed). Language and culture, Work papers of Summer Institute of Linguistics-Australian Aborigines Branch, Series B, (Vol. 8, pp. 3356). Darwin: Summer Institute of Linguistics-Australian Aborigines Branch. Retrieved from http://www.aiatsis.gov.au/lbry/dig_prgm/e_access/serial/m0022785_v_p33to56_a . $\mathrm{pdf}$

Strehlow, T. (1944). Arranda phonetics and grammar, Oceania monographs no. 7. Sydney: The Australian National Research Council.

Treacy, K., \& Frid, S. (2008). Recognising different starting points in Aboriginal students' learning of number. In M. Goos, R. Brown, and K. Maker (Eds.), Proceedings of the 31st Annual Conference of the Mathematics Education Research Group of Australasia (pp 531-537). St Lucia: University of Queensland Press.

Warren, E., deVries E., \& Cole, A. (2009). Closing the gap: Myths and truths behind subitisation. Australasian Journal of Early Childhood, 34(4). 46-5.

Watson, H. (1988). Language and mathematics education for Aboriginal Australian children. Language and Education, 2, 255-273.

Woerlee, B. (2000). Chapter 2: Kudnarto. Retrieved from http://kudnarto.tripod.com/ch2.htm

Zaslavsky, C. (1973). Africa counts: Number and pattern in African culture. Boston: Prindle, Weber and Schmidt. 